\title{
Monitoring System of Shaft Based on ZigBee Wireless Sensor Network
}

\author{
Man-hong FAN, Sheng-qian MA
}

Key Laboratory of Atomic and Molecular Physics \& Functional Materials of Gansu Province, College of Physics and Electronic Engineering, Northwest Normal University. Anning East Road 967, Lanzhou, China

\begin{abstract}
Traditional shaft temperature and humidity detection system is wired mode, the transmission distance is limited. In order to overcome this shortcoming, this paper designed a detection system, which is based on ZigBee wireless sensor network and digital temperature-humidity sensor. In the system, the data's acquisition and transmission of master-slave nodes is realized by the star network, and the data is displayed on the host computer through serial port. The system can realize multi-point detection and real-time monitoring.
\end{abstract}

\section{Introduction}

The function of the monitoring system mainly includes collection, master, alarming, information transmitting and host computer displayed. Sensor is the perception of the monitoring system, which can transform the information into electrical signals, and then the system can collect, transmit and analyze these signals, which can indirectly reflect the state of the underground environment; The main system not only control to extract the information of sensor and transmit the data to the channel of communication, but also need to determine whether the collected information is normal. If the collected information out of range, the master will carry out the alarm. The part of information transmitting is responsible for sending the collected data to the host computer smoothly and displayed on it. Make sure, transmit information of data is effectively and timely. On the PC will display the data received in real time. In order to monitor the state of the underground environment all the time. The host computer by judging the machine over the information of data, displays that the state of underground environment is normal or abnormal, the alarm will rang when the data exceed the normal range.

The application of wireless environmental monitoring system is very extensive. Dohare(2015) uses the wireless Communication and Environment Monitoring in Underground Coal Mines. According to MASHALKAR and KAZI (2015), learning more about Smart Dust. Jha (2014) puts the networked Sensors on the architecture. Egan(2005) is used the ZigBee to automation and industrial controlling. Lee and SuA(2007) studies the wireless in Bluetooth. Alliance(2009) introduces the ZigBee standard.

\section{Hardware design of the system}

This system mainly involves the following modules: the master control of STM32, temperature and humidity sensor, LCD screen, JTAG interface, Clock and reset, wireless communication of ZigBee and power supply. Figure 1 is diagram of the system.

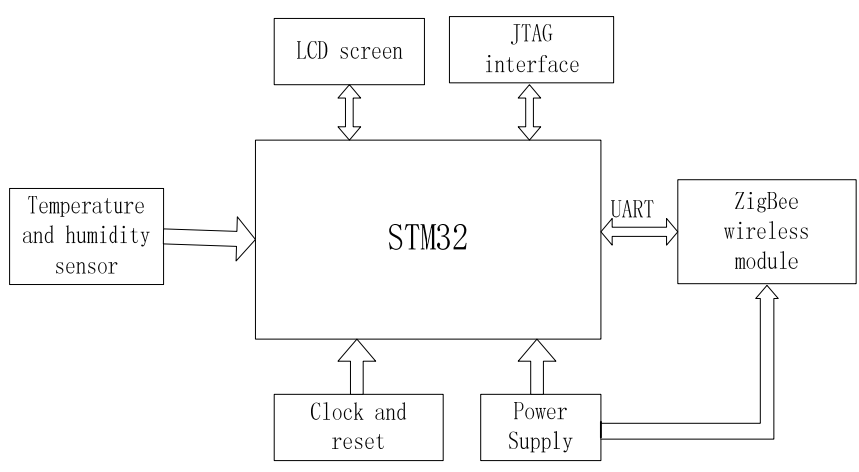

Fig 1. diagram of the system

\subsection{The processor}

STM32 is a microprocessor chip which is based on ARM Cortex-M3 kernel. The chip has the advantages of strong compatibility, high integration, strong real-time, which is easy to hardware development. Figure 2 is the STM32 Minimum system schematic. Table 1 is STM32 standard performance.

Before the STM32F105 and STM32F107 interconnected series of micro controllers, Italy semiconductor has introduced the STM32 basic series, the enhanced series, the USB basic series, the complementary series; the new series products follow the $72 \mathrm{MHz}$ processing frequency of the enhanced series. The memory includes $64 \mathrm{~KB}$ to $256 \mathrm{~KB}$ flash memory and $20 \mathrm{~KB}$ to $64 \mathrm{~KB}$ embedded SRAM. The new series uses three packages of LQFP64, LQFP100 and 
LFBGA100. Different packages keep the consistency of pin arrangement. In combination with the design concept of STM32 platform, the developer can reoptimize function, memory, performance and pin number by selecting the product to meet the personalized application requirements with minimal hardware change.

The STM32L series added low power consumption and low power sleep two low power modes. By using the ultra-low power voltage regulator and oscillator, the micro controller can greatly reduce the power consumption at low frequency. The regulator can satisfy the current requirement without depending on the supply voltage. STM32L also provides dynamic voltage lifting, which is a successful application of energy saving technology for many years, which can further reduce the internal working voltage of the chip in the middle and low frequency operation. Under normal operation mode, the minimum current consumption of flash memory is $230 \mathrm{~A} / \mathrm{MHz}$, and the power consumption / performance ratio of STM32L is the lowest $185 \mathrm{~A} / \mathrm{DMIPS}$.
Table 1. STM32 standard performance

\begin{tabular}{|c|c|c|}
\hline Number & Function & Parameter \\
\hline 1 & Clock frequency & $72 \mathrm{MHz}$ \\
\hline 2 & Interrupt mode & interrupt nesting \\
\hline 3 & Voltage range & $2.0 \sim 3.6 \mathrm{~V}$ \\
\hline 4 & $\begin{array}{c}\text { Lowest power } \\
\text { consumption in standby } \\
\text { mode }\end{array}$ & $2 \mathrm{uA}$ \\
\hline
\end{tabular}

\subsection{ZigBee wireless sensor network}

CC2530 is a real system on chip (SoC) solution for 2.4GHz IEEE 802.15.4, ZigBee and RF4CE applications. It can build strong network nodes with very low total material cost.

CC2530 combines the excellent performance of the leading RF transceiver, industry standard enhanced 8051 CPU, programmable flash memory in the system, 8-KB RAM and many other powerful functions. CC2530 has four different flash versions: CC2530F32/64/128/256,

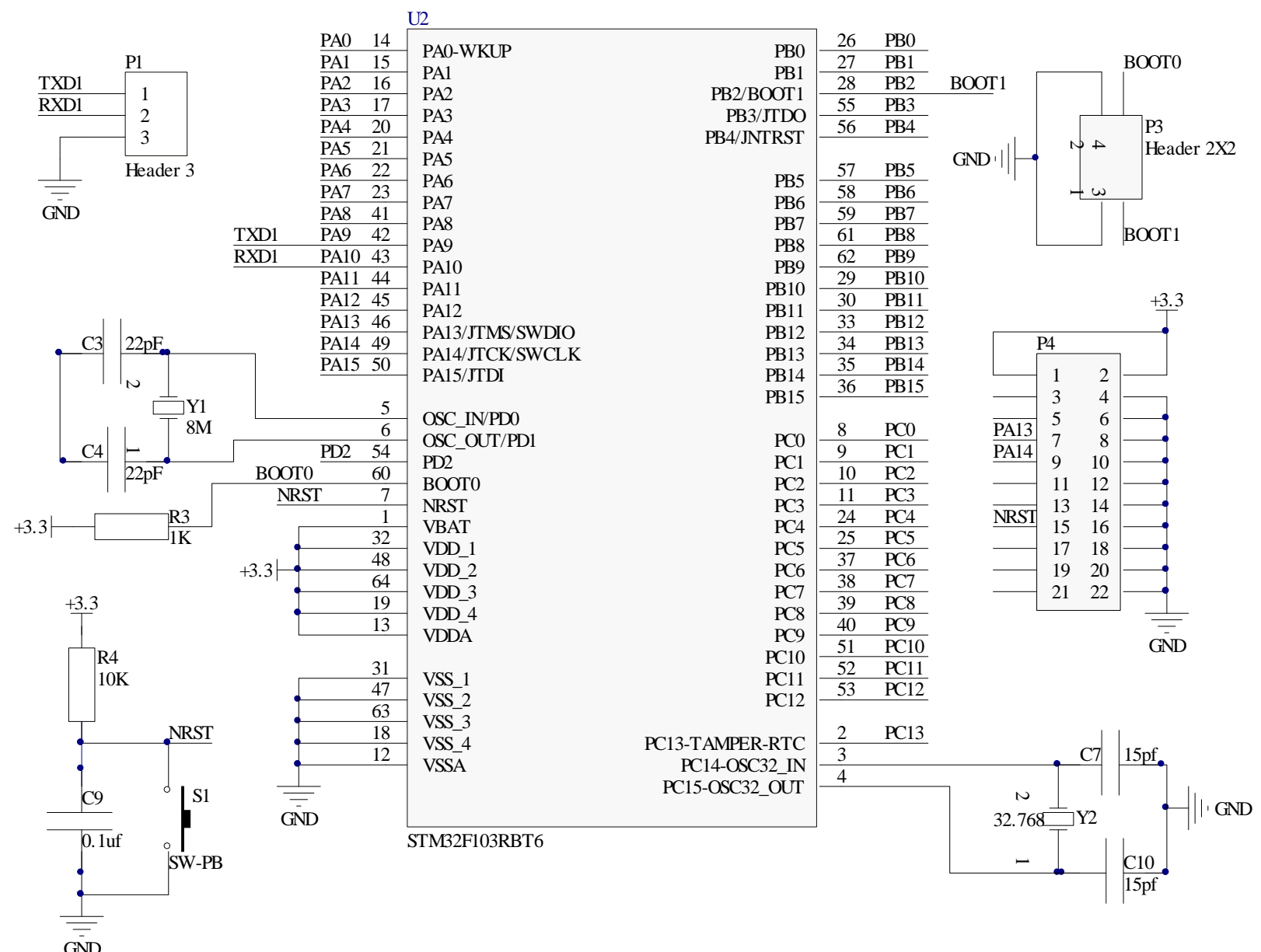

Fig 2. STM32 Minimum system schematic 
64/128/256KB respectively. CC2530 has different modes of operation, making it especially suitable for ultra-low power consumption systems. Short switching time between operation modes further ensures low energy consumption.

CC2530 has a IEEE 802.15.4 compatible wireless transceiver. The RF kernel controls the analog wireless module. In addition, it provides an interface between the MCU and the wireless device, which makes it possible to send commands, read States, automatically operate and determine the order of wireless device events. The wireless device also includes a packet filter and address recognition module.

The communication of data between the nodes of network in the sensor must be carried out through the wireless communication. This design is based on CC2530 [7-8]. Although low-cost, it can build a powerful wireless sensor network node. CC2530 can be switched to a different mode in a short period of time, particularly suitable for low power consumption requirements of the application. CC2530 includes the abundant resources of hardware in the internal, the main function module is: the enhanced 8051 core, the memory, the RF transceiver, the $\mathrm{A} / \mathrm{D}$, the timer, USART, $\mathrm{I} / \mathrm{O}$, DMA controller, AES security coprocessor. The connection pin of CC2530 and STM32 is shown in Figure 3.

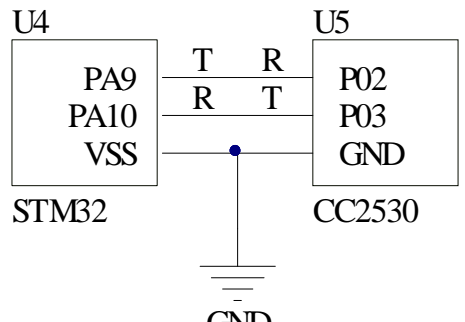

Fig 3. Connection of CC2530 and STM32

\subsection{Temperature and humidity sensor}

DHT22 is a type of high precision digital temperature and humidity sensor. The sensor includes capacitive humidity sensitive element and a high precision temperature measuring element. Each sensor has completed the temperature calibration before delivery, and will be stored the calibration coefficient in the 8 bits microcontroller chip. Each sensor uses internal form calling these calibration coefficients internal to process collected signal. Figure 4 is the diagram of pins' connection of DHT22.

In Han and $\mathrm{Li}(2009)$, point out the design of Temperature And Humidity Detection System for Intelligent Community. Wei(2012) studies the wireless network sensing system bases on ZigBee.

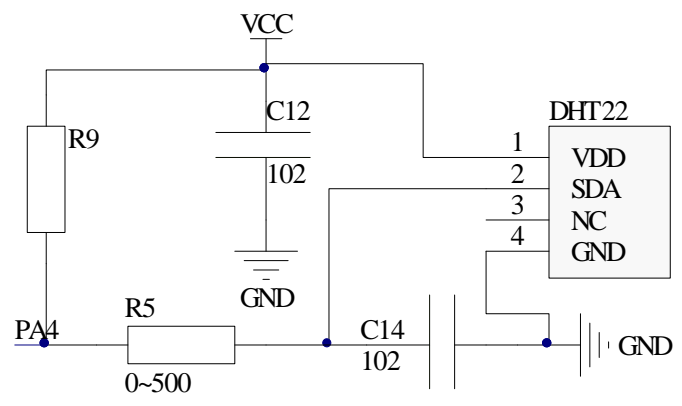

Fig 4. DHT22 connection

\section{The software design of the system}

\subsection{Main program design}

The software design for STM32 and sensor acquisition uses the MDK5.10. Keil MDK integrates industryleading technology, including the integrated developing environment of Keil Vision5 with RealView compiler, which supports ARM7, ARM9 and the latest Cortex-M3 core processor. The software design includes data's acquisition of the route and the sensor of terminal node, transmission of serial and transmission of ZigBee, and the coordinator node by the RS485 that will transfer the data to the host computer. The flow chart of main program is shown in Figure 5.

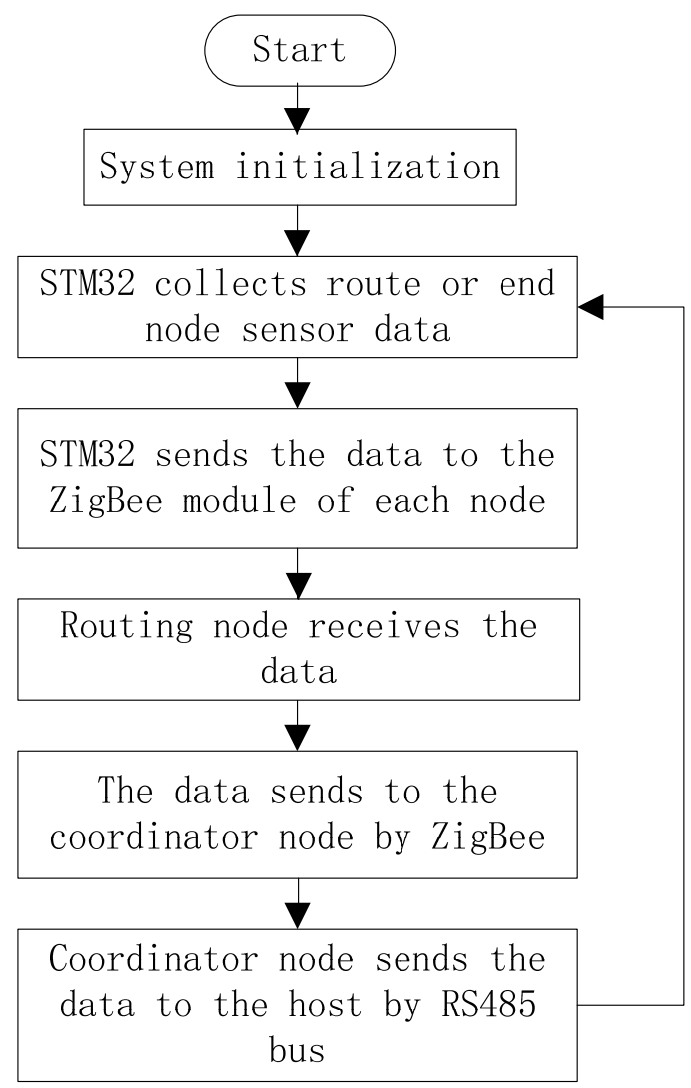

Fig 5. Main program flow chart

STM32 controls the sensor's 5 parameters cycle and time-share collection. If the range is out of the alarm, the 
result will be displayed by the LCD, and the data that has read is transmitted to the ZigBee module through the serial port, after the data of ZigBee network transmission come to the node of coordinator, and it will be transferred to the host computer through RS485.

\subsection{DHT22 data collection}

When in the idle state, the bus is high level. STM32 pull bus level to low, when the signal starting, then it will release bus. Time delay about $20 \sim 40 \mu$ s, loop detecting DHT22 signal will begin. This signal is about $80 \mu \mathrm{s}$ low level response. When received the signal, STM32 will collect the 40 bit data. Finally, LCD and serial port is opened. Figure 6 is the DHT22 Software process.

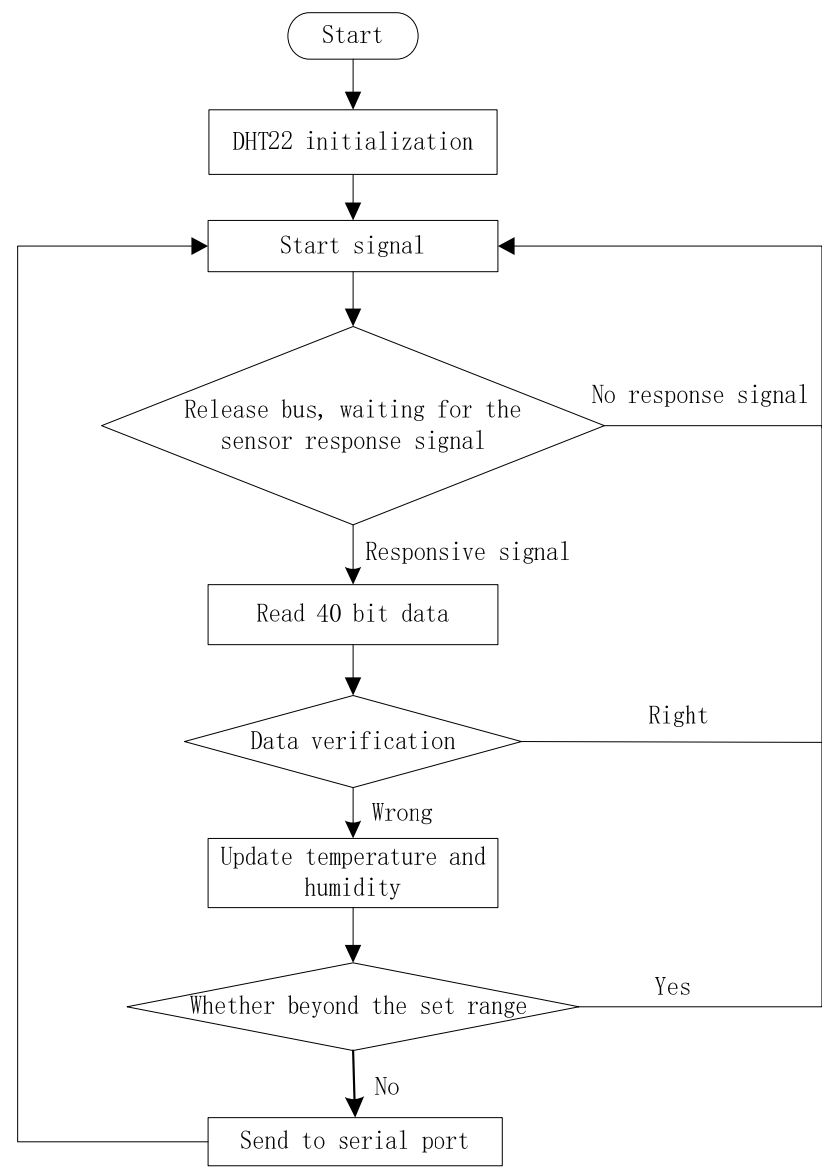

Fig 6. DHT22 Software process

\section{Experimental test}

The system can be applied to the 17 floors' experimental building. The host computer is in the 17th floor. In order to facilitate testing, the part of power use the mobile power of $5 \mathrm{~V}$, the specific situation may need to use the battery of voltage or $9 \sim 12$ DC power of supply regulator, or directly use the computer USB power to supply. The data collection location is on the first floor and the 9th floor. Each floor was collected 10 different points of the temperature and humidity. Table 2 shows the information of data to the temperature and humidity in the first floor, in Table 3 for the data of information to the temperature and humidity in the 9th floor.

Table 2. Data information in the first floor

\begin{tabular}{|c|c|c|c|c|c|}
\hline $\begin{array}{c}\text { Test } \\
\text { number }\end{array}$ & $\mathbf{1}$ & $\mathbf{2}$ & $\mathbf{3}$ & $\mathbf{4}$ & $\mathbf{5}$ \\
\hline $\begin{array}{c}\text { Temperature } \\
\left({ }^{\circ} \mathrm{C}\right)\end{array}$ & 17.5 & 18.9 & 17.1 & 20.4 & 21.2 \\
\hline $\begin{array}{c}\text { Humidity } \\
(\% \mathrm{RH})\end{array}$ & 32.9 & 35.7 & 36.1 & 35.9 & 35.4 \\
\hline $\begin{array}{c}\text { Test } \\
\text { number }\end{array}$ & $\mathbf{6}$ & $\mathbf{7}$ & $\mathbf{8}$ & $\mathbf{9}$ & $\mathbf{1 0}$ \\
\hline $\begin{array}{c}\text { Temperature } \\
\left({ }^{\circ} \mathrm{C}\right)\end{array}$ & 19.5 & 18.9 & 21.4 & 22.0 & 21.7 \\
\hline $\begin{array}{c}\text { Humidity } \\
(\% \mathrm{RH})\end{array}$ & 34.2 & 36.1 & 35.8 & 37.1 & 34.2 \\
\hline
\end{tabular}

Table 3. Data information in the 9th floor

\begin{tabular}{|c|c|c|c|c|c|}
\hline $\begin{array}{c}\text { Test } \\
\text { number }\end{array}$ & $\mathbf{1}$ & $\mathbf{2}$ & $\mathbf{3}$ & $\mathbf{4}$ & $\mathbf{5}$ \\
\hline $\begin{array}{c}\text { Temperature } \\
\left({ }^{\circ} \mathrm{C}\right)\end{array}$ & 27.9 & 29.3 & 29.5 & 28.6 & 27.5 \\
\hline $\begin{array}{c}\text { Humidity } \\
(\% \mathrm{RH})\end{array}$ & 39.1 & 38.7 & 39.4 & 38.9 & 40.0 \\
\hline $\begin{array}{c}\text { Test } \\
\text { number }\end{array}$ & $\mathbf{6}$ & $\mathbf{7}$ & $\mathbf{8}$ & $\mathbf{9}$ & $\mathbf{1 0}$ \\
\hline $\begin{array}{c}\text { Temperature } \\
\left({ }^{\circ} \mathrm{C}\right)\end{array}$ & 28.9 & 28.4 & 28.9 & 29.1 & 28.0 \\
\hline $\begin{array}{c}\text { Humidity } \\
(\% \mathrm{RH})\end{array}$ & 39.9 & 38.1 & 39.8 & 37.9 & 37.6 \\
\hline
\end{tabular}

\section{Conclusion}

In this paper, the detected system of the CC2530 wireless temperature and humidity is based on ZigBee technology, and the 20 sensor nodes of the temperature and humidity are studied. In the experimental building, the detection of multipoint data wireless transmission are realized. The results meet the expected requirements. The system has a simple structure, low power, high effective detection, and good ability of anti-interference, which has the higher practical and economic benefit. 


\section{Acknowledgment}

In this paper, the research was sponsored by the Natural Science Foundation of China ( 61162017 ), Department of Education-fund projects in Gansu(1101-03).

\section{References}

1. Alliance Z.B. IEEE 802.15. 4, ZigBee standard. http://www. zigbee. org. ( 2009)

2. Dohare Y.S., Maity T., Das P.S., et al. Wireless Communication and Environment Monitoring in Underground Coal Mines-Review. IETE Technical Review.1-11. (2015)

3. Egan D. The Emergence of ZigBee in building automation and industrial controls. Computing and Control Engineering.16(2), 14-19. (2005)

4. Jha L.N. System Architecture Directions for Networked Sensors. International Journal of Research. 1(11), 450-465. (2014)
5. Lee J.S., Su Y.W.and Shen C.C. A comparative study of wireless protocols: Bluetooth, UWB, ZigBee, and Wi-Fi. Industrial Electronics Society, 2007. IECON 2007. 33rd Annual Conference of the IEEE. Taipei, Taiwan, Nov.05-08, IEEE. 46-51. (2007)

6. MASHALKAR Y.S. and KAZI A.S.M. Wirless Sensor Networks (MOTES): Smart Dust. IJCER, 3(6), 308-312. (2015)

7. Han Chenghao, Li Baifeng, et al. Design of Temperature And Humidity Detection Systemfor Intelligent Community. Journal of Changchun University of Science and Technology(Natural Science Edition). 32(3), 494-497. (2009)

8. Wei Feifei. Research of The Wireless Network Sensing System Bases on ZigBee. Dalian Maritime University. (2012) 